\title{
The association between sleep disturbances and suicidal behaviors in patients with psychiatric diagnoses: a systematic review and meta-analysis
}

\author{
Shaista Malik ${ }^{1,2}$, Amrit Kanwar ${ }^{3}$, Leslie A Sim ${ }^{4}$, Larry J Prokop ${ }^{5}$, Zhen Wang ${ }^{6,7,8^{*}}$, Khalid Benkhadra ${ }^{7}$ \\ and Mohammad Hassan Murad ${ }^{1}$
}

\begin{abstract}
Background: Identifying patients with increased risk of suicidal behaviors is a constant challenge and concern for clinicians caring for patients with psychiatric conditions. We conducted a systematic review to assess the association between suicidal behaviors and sleep disturbances in psychiatric patients.

Methods: A systematic literature search of Ovid Medline In-Process \& Other Non-Indexed Citations, Ovid MEDLINE, Ovid EMBASE, Ovid PsycInfo, Ovid Cochrane Database of Systematic Reviews, Ovid Cochrane Central Register of Controlled Trials, and Scopus was conducted using earliest inclusive dates to 28 June 2013. Eligible studies were comparative observational studies that reported sleep disturbances in psychiatric patients and the outcome of interest (any type of suicidal behaviors). Pairs of reviewers extracted descriptive data, study quality, and outcomes. Odds ratios (OR) and 95\% confidence intervals $(\mathrm{Cl})$ were pooled across studies using the random-effects model. Newcastle-Ottawa scale was used to critically appraise study quality.

Results: Nineteen studies met the inclusion criteria. Compared to those without sleep disturbances, patients with psychiatric diagnoses and co-morbid sleep disturbances were significantly more likely to report suicidal behaviors $(\mathrm{OR}=1.99,95 \% \mathrm{Cl} 1.72,2.30, P<0.001)$. The association was also demonstrated across several psychiatric conditions including depression $(\mathrm{OR}=3.05,95 \% \mathrm{Cl} 2.07,4.48, P<0.001)$, post-traumatic stress disorder (PTSD) $(\mathrm{OR}=2.56,95 \% \mathrm{Cl}$ $1.91,3.43, P<0.001)$, panic disorder $(\mathrm{OR}=3.22,95 \% \mathrm{Cl} 1.09,9.45, P=0.03)$, and schizophrenia $(\mathrm{OR}=12.66,95 \% \mathrm{Cl}$ $1.40,114.44, P=0.02)$. In subgroup analysis based on the type of sleep disorder, we also found suicidal behavior to be significantly associated with the presence of insomnia, parasomnias, and sleep-related breathing disorders, but not hypersomnias.
\end{abstract}

Conclusions: This systematic review and meta-analysis suggests that in patients with psychiatric diagnoses, sleep disturbances are associated with the increased risk of suicidal behaviors.

Keywords: Sleep disturbances, Suicidal behaviors, Systematic reviews, Meta-analysis

\section{Background}

Psychiatric patients are thought to be at high risk of suicidal behaviors. However, clinicians face challenges of identifying patients at risk [1]. The literature suggests that the severity of psychiatric illness is not always predictive of suicide attempts [2]; and the sensitivity and specificity of risk

\footnotetext{
* Correspondence: wang.zhen@mayo.edu

${ }^{6}$ Division of Health Care Policy and Research, Department of Health Sciences Research, Mayo Clinic, Rochester, USA

${ }^{7}$ Mayo Clinic Robert D. and Patricia E. Kern Center for the Science of Health Care Delivery, Rochester, USA

Full list of author information is available at the end of the article
}

factors, including gender, prior suicide attempts, and suicidal ideations, remain low in predicting future suicide [3]. There is a great need to find additional risk factors. Given that sleep disturbances are fairly common in psychiatric patients, it is suggested that sleep disturbances may constitute a modifiable risk factor for suicidal behaviors $[4,5]$.

Direct relationship between sleep disturbances and suicide has been evaluated in multiple studies. A recent systematic review and meta-analysis of 39 studies found patients with sleep problems had significantly increased risk of suicidal ideations, suicide attempts, and completed 
suicides [6]. That study focused on the general population although it reported that depression did not moderate the association between sleep and suicide. However, other studies found significant associations between suicides and sleep disturbances among psychiatric patients. A study of 954 patients with affective disorders found that global insomnia was significantly associated with attempted suicide [1]. In another study, both insomnia and hypersomnia had prognostic significance in predicting suicide among patients with major depression [7]. Moreover, in an epidemiologic prospective study of 1,231 psychiatric outpatients, nocturnal sleep disturbances, particularly frequent insomnia and recurrent nightmares, were independently associated with enhanced suicidal risk [8].

Considering the lack of a systematic review that focuses on the effect of sleep on suicide risk in patients with psychiatric conditions and the conflicting results from the literature, we conducted this study to assess the association between suicidal behaviors and sleep disturbances in psychiatric patients.

\section{Methods}

A review protocol was developed at the beginning of this study. The reporting of this systematic review is in accordance with the Preferred Reporting Items for Systematic Reviews and Meta-analyses (PRISMA) statement [9].

\section{Inclusion and exclusion criteria}

Eligible studies were comparative observational studies that reported sleep disturbances in psychiatric patients and the outcome of interest (any type of suicidal behaviors). We used the original study's definition of sleep disturbances, which ranged from snoring, nightmares, hypersomnia insomnia, sleep panic attacks, and sleep deprivation. With respect to suicidal behaviors, we include suicide ideations, suicide attempts, completed suicides, and any other suicidal behaviors defined by the original studies. Studies were excluded if they did not report outcomes for psychiatric patients or did not provide sufficient data to quantitatively estimate the association between suicidal behaviors and sleep disturbances. We also excluded publications without original data (clinical reviews, editorials, letters, or erratum). No language or country restrictions were used.

\section{Data sources and search strategy}

An expert reference librarian and study authors with expertise in conducting systematic reviews developed the search strategy. A comprehensive search of databases from each database's earliest inclusive dates to 26 June 2013 was conducted. The databases included Ovid Medline In-Process \& Other Non-Indexed Citations, Ovid MEDLINE, Ovid EMBASE, Ovid PsycInfo, Ovid
Cochrane Database of Systematic Reviews, Ovid Cochrane Central Register of Controlled Trials, and Scopus. Controlled vocabulary, supplemented with keywords, was used to search for the concept areas: suicide, sleep disorders, and psychiatric conditions. The database search strategy is available in Additional file 1. We also searched additional references from a recent systematic review [6].

\section{Study selection and data extraction}

Reviewers working independently and in duplicate assessed each abstract for eligibility. Disagreements yielded an automatic inclusion into the following level of screening. Included studies were retrieved and full text screening commenced in duplicate as well. Disagreements at this level were resolved by discussion and consensus. Two reviewers working independently and in duplicate extracted baseline and outcome data and assessed the quality of each included study. A third reviewer compared the reviewers' data and resolved inconsistencies by referring to the full text article.

Reviewers independently extracted study details from the full text articles, using a pilot-tested form. The following data were abstracted: study design, country, patient characteristics (sex, age), psychiatric diagnoses, sleep disturbances, and suicidal behaviors. We extracted numbers of patients with outcomes (suicidal behaviors) at the longest duration of complete follow-up.

\section{Assessment of study quality and publication bias}

Using the Newcastle-Ottawa scale, we assessed the quality of included observational studies by determining outcome ascertainment, adjustment for confounders, and proportion of patients lost to follow-up as well as sample selection. We assessed potential publication bias by visual inspection of funnel plots and the Egger's regression asymmetry tests.

\section{Statistical analysis}

The outcome of interest was suicidal behaviors, including suicidal ideations, suicide attempts, and completed suicides. Outcomes were either dichotomized by the individual study or when presented as a scale, were converted to $\log$ transformed OR ( $\log \mathrm{OR}$ ) based on the commonly used formula suggested by Borenstein et al. [10].

We pooled the $\log \mathrm{OR}$ from all of the included studies using the DerSimonian \& Laird random effects method with the estimate of heterogeneity from the MantelHaenszel model [11]. We conducted a priori planned subgroup analysis based on the type of suicidal behaviors (ideations, attempts, and completed suicides). We subsequently evaluated separately the different types of sleep disturbances (insomnia, hypersomnia, parasomnia, sleeprelated breathing disorders, and mixed/unclear types) to further explore heterogeneity across studies. When one 
study reported outcomes for multiple subgroups, these outcomes were pooled separately in each subgroup. When multiple outcomes were reported in one subgroup, we chose the one that clearly defined and/or objectively measured.

We used the $\mathrm{I}^{2}$ statistic to measure heterogeneity across the studies. Statistical analyses were conducted using STATA version 12 (StataCorp, College Station, TX, USA) and $\mathrm{R}$ software version 3.0.1 (R Foundation for Statistical Computing, Vienna, Austria).

\section{Results}

\section{Description and quality of included studies}

Our search identified 372 candidate references (Figure 1). After deleting duplicated studies and excluding irrelevant studies, 19 studies met the inclusion criteria and were included in this analysis. The characteristics of these studies are summarized in Table 1. Overall, 104,436 patients were included in this review. The average age was 49.4 years (range, 17-79 years). Fifty-eight percent of the patients were female. The average length of follow-up in the prospective studies was 9.9 years (range, 3 days - 27 years). Of 19 studies, $13(68.4 \%)$ reported outcomes in depressive patients. The other psychiatric diagnoses included were post-traumatic stress disorder (PTSD), panic disorder, schizophrenia, and anxiety. Eleven studies (57.9\%) were prospective studies, four $(21.1 \%)$ were cross-sectional, and three $(15.87 \%)$ were retrospective.

Figure 2 shows the quality indicators of the included studies. We found variable quality across studies. Most (68.4\%) of the studies did not adjust for risk factors. However, 15 studies reported low risk of bias for the ascertainment of outcomes. Using the Egger regression asymmetry test and visual inspection of the funnel plot, we found potential publication bias in this body of evidence. Across the included studies, substantial heterogeneity was observed in most of the pooled outcomes (>50\%) [28]. In summary, the risk of bias is moderate to high due to potential publication bias and substantial heterogeneity.

Figure 3 shows the pooled odds ratios (ORs) from all of the included studies. Compared to those without sleep disturbances, patients with psychiatric diagnoses and co-morbid sleep disturbances were significantly more likely to report suicidal behaviors $(\mathrm{OR}=1.99,95 \% \mathrm{CI}$ 1.72 , 2.30, $P<0.001)$. Regarding to specific psychiatric conditions, we found strong association between suicidal behaviors and sleep disturbances in depression $(\mathrm{OR}=3.05$, 95\% CI 2.07, 4.48, $P<0.001$ ), PTSD (OR $=2.56,95 \% \mathrm{CI}$ 1.91, 3.43, $P<0.001$ ), panic disorders $(\mathrm{OR}=3.22,95 \% \mathrm{CI}$ $1.09,9.45, P=0.03)$, and schizophrenia $(\mathrm{OR}=12.66,95 \%$ CI $1.40,114.44, P=0.02$ ). Table 2 shows the pooled OR for different suicidal behaviors. Sleep disturbances were also significantly associated with suicide ideations, suicide attempts, and completed suicides. Subgroup analysis based on the type of sleep disturbance showed that insomnia, parasomnia, and sleep-related breathing disorders were significantly associated with increased risk of suicidal behaviors (Table 3). The only exception was hypersomnias $(\mathrm{OR}=1.91,95 \% \mathrm{CI}: 0.60,6.06, P=0.27)$.

\section{Discussion}

We conducted a systematic review and meta-analysis to investigate the association between the presence of sleep disturbances and risk of suicidal behaviors in patients with psychiatric diagnoses. Nineteen studies with 104,436 patients were included in the analysis. We found significantly increased risk of suicidal behaviors among patients

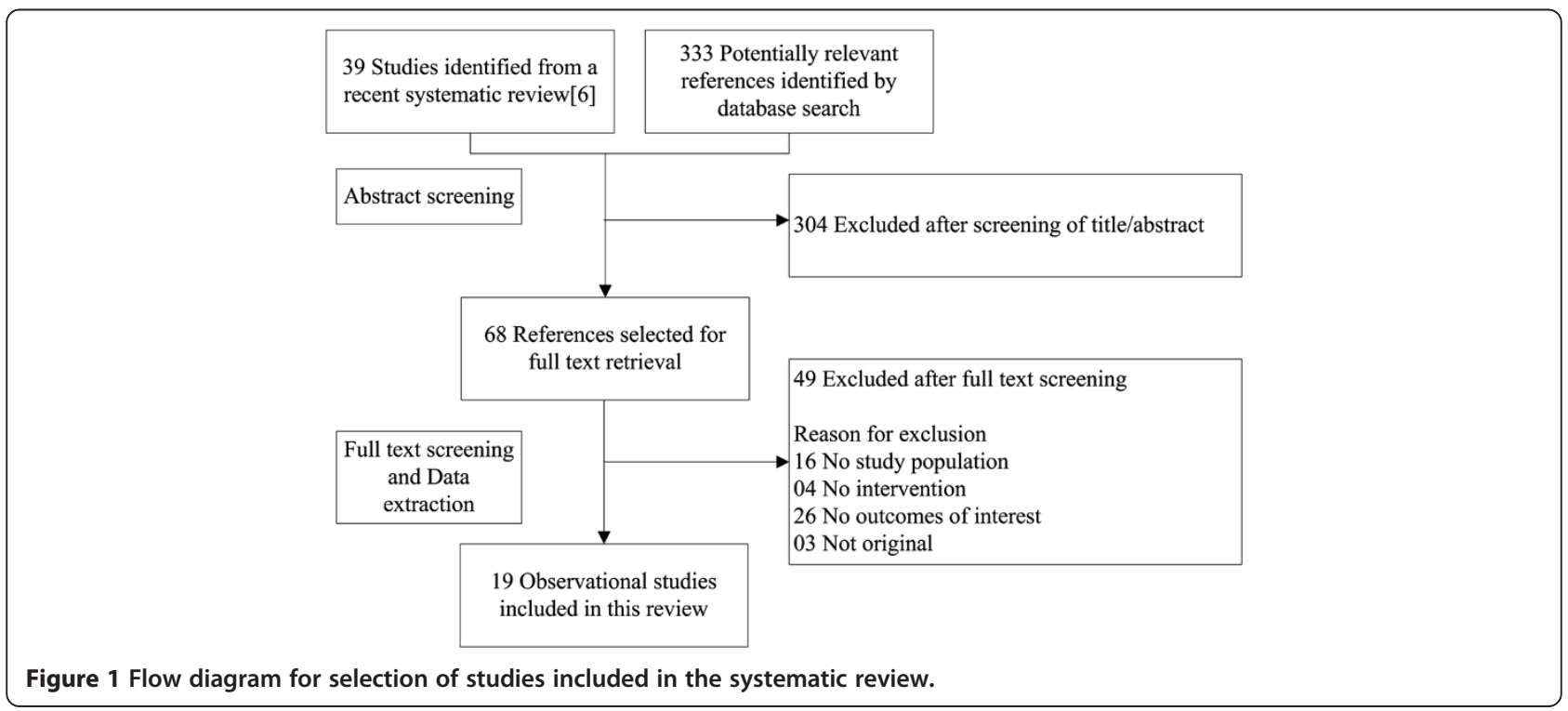


Table 1 Basic characteristics of the included studies

\begin{tabular}{|c|c|c|c|c|c|c|c|}
\hline Author, year & $\begin{array}{l}\text { Study } \\
\text { design }\end{array}$ & $\begin{array}{l}\text { Patients } \\
\text { (n) }\end{array}$ & $\begin{array}{l}\text { Female } \\
(\%)\end{array}$ & Age (years) & Psychiatric diagnoses & Suicidal behaviors & Sleep disturbances \\
\hline $\begin{array}{l}\text { Agargun, } 1997 \text { [7] } \\
\end{array}$ & Retrospective & 113 & $74 \%$ & Mean: 32.6 range: $18-70$ & Major depression & Ideation & Insomnia and hypersomnia assessed by SCID-I \\
\hline Li, $2010[8]$ & Cross-sectional & 1,231 & $68.20 \%$ & Mean: 42.4, range 18-65 & $\begin{array}{l}\text { Major depression, } \\
\text { Bipolar, Other }\end{array}$ & Attempt & $\begin{array}{l}\text { Self-reported insomnia and recurrent nightmares } \\
\text { assessed by a questionnaire }\end{array}$ \\
\hline McGirr, 2007 [12] & Prospective & 156 & $19.20 \%$ & Mean: 42.4 & Major depression & Completed suicide & Insomnia and hypersomnia assessed by SCID-I \\
\hline Nrugham, 2008 [13] & Prospective & 2,464 & $50.80 \%$ & Mean age 13.7 & $\begin{array}{l}\text { Depressive symptom } \\
\text { and disorder }\end{array}$ & Ideation, attempt & $\begin{array}{l}\text { Insomnia, hypersomnia, non-restorative sleep } \\
\text { assessed by K-SADS and MFQ }\end{array}$ \\
\hline Paffenbarger, 1994 [14] & Prospective & 21,582 & 0 & Range: $35-74$ & Depressive disorder & Completed suicide & Self-reported insomnia assessed by a questionnaire \\
\hline Pompili, 2009 [15] & Retrospective & 40 & $10 \%$ & Mean: 40 Range: $23-76$ & Schizophrenia & Completed suicide & $\begin{array}{l}\text { Insomnia defined as difficulty initiating or maintaining } \\
\text { sleep, or non-restorative sleep causing impaired } \\
\text { functioning or suffering that was long-lasting or } \\
\text { demanded treatment and recorded from patients' } \\
\text { medical records }\end{array}$ \\
\hline Sjostrom, $2009[16]$ & Prospective & 165 & $78 \%$ & Range: $18-69$ & Axis 1 DSM disorders & Attempt & $\begin{array}{l}\text { Difficulties initiating sleep, problems maintaining sleep } \\
\text { and early morning awakening assessed by USI }\end{array}$ \\
\hline Agargun, 1997 [17] & Prospective & 41 & $76 \%$ & Mean: 34.6 SD: 10.8 & Major depression & $\begin{array}{l}\text { SADS suicidality } \\
\text { score }\end{array}$ & $\begin{array}{l}\text { Subjective sleep quality, sleep latency, sleep duration, } \\
\text { habitual sleep efficiency, sleep disturbance, use of } \\
\text { sleeping medications, daytime dysfunction, and global } \\
\text { severity measured by PSQI }\end{array}$ \\
\hline Agargun, 1998 [18] & Prospective & 63 & $76 \%$ & Mean: 34.1 SD: 10.8 & Major depression & Ideation, attempts & Frequency of nightmares \\
\hline Agargun, 1998 [19] & Unclear & 67 & $73.10 \%$ & Mean: 31.9 SD: 8.8 & Panic disorder & Ideation & Sleep panic and insomnia ascertained from SADS \\
\hline Agargun, 2003 [20] & Prospective & 26 & $61.50 \%$ & Unclear & Major depression & HDRS suicide scores & $\begin{array}{l}\text { REM latency, REM\%, REM periods measured by three } \\
\text { nights of polysomnography }\end{array}$ \\
\hline Chellappa, 2007 [21] & Cross-sectional & 70 & $62.90 \%$ & Mean:: 40.5 SD: 12.54 & Major depression & Ideation & $\begin{array}{l}\text { Insomnia or excessive sleepiness assessed by the } \\
\text { SHQ and ICSD }\end{array}$ \\
\hline Krakow, 2000 [22] & Prospective & 153 & $100 \%$ & Mean: 36.4 SD: 11.1 & PTSD & $\begin{array}{l}\text { Hamilton Depression } \\
\text { and suicidality scores }\end{array}$ & SMD and SDB assessed by AASM 1997 and ASDA 1997 \\
\hline Agargun, 2007 [23] & Retrospective & 100 & $52 \%$ & Mean: 32.1 SD: 10.7 & $\begin{array}{l}\text { Unipolar major } \\
\text { depression }\end{array}$ & Attempt & $\begin{array}{l}\text { Nightmares assessed by ICSD-R; insomnia assessed by } \\
\text { the HDRS items } 6,7 \text {, and } 8\end{array}$ \\
\hline Yoshimasu, 2006 [24] & Cross-sectional & 231 & $57.10 \%$ & Mean: 36.3 SD: 28.5 & Major depression & Ideation & $\begin{array}{l}\text { Insomnia assessed by SDS, KMI, and patients' three } \\
\text { most painful complaints }\end{array}$ \\
\hline Bjorngaard 2011 [25] & Prospective & 74,977 & $51 \%$ & Mean: 37.9 SD: 16.0 & Anxiety, depression & Completed suicide & $\begin{array}{l}\text { Self-reported sleep difficulties assessed by a } \\
\text { questionnaire }\end{array}$ \\
\hline
\end{tabular}


Table 1 Basic characteristics of the included studies (Continued)

\begin{tabular}{|c|c|c|c|c|c|c|c|}
\hline Li 2012 [26] & Prospective & 419 & $81.80 \%$ & Mean: 44.6 SD: 10.4 & Major depression & Ideation & $\begin{array}{l}\text { Insomnia, nightmares, and frequency of sleep } \\
\text { disturbances measured by a questionnaire }\end{array}$ \\
\hline Krakow 2011 [27] & Cross-sectional & 1,584 & $55 \%$ & Mean: 49.8 SD: 66.4 & Depression & Attempt & $\begin{array}{l}\text { Sleep disturbances measured by SMH, ISI DDNSI, } \\
\text { FOSQ, and TMB-10 }\end{array}$ \\
\hline Fawcett, 1990 [1] & Prospective & 954 & $58 \%$ & Mean: 38.1 Range: 17-79 & Major affective disorder & Completed suicide & Insomnia assessed by SADS \\
\hline
\end{tabular}

AASM: American Academy of Sleep Medicine; ASDA: American Sleep Disorders Association; DDNSI: Disturbing Dream and Nightmare Severity Index; FOSQ: Functional Outcomes Sleep Questionnaire; HDRS: Hamilton Depression Rating Scale; ICSD: International Classification of Sleep Disorders diagnostic criteria for sleep disorders due to mood disorders; ICSD-R: International Classification of Sleep Disorders, revised; ISI: Insomnia Severity Index; KMI: Kyudai Medical Inventory; K-SADS: Kiddie-Schedule for Affective Disorders and Schizophrenia; MFO: Mood and Feelings Questionnaire; PSOl: Pittsburgh Sleep Ouality Index: PTSD: Post-traumatic stress disorder; REM: Rapid eye movement; SADS: Schedule for Affective Disorders and Schizophrenia; SCID-I: Structured Clinical Interview for DSM-IV-TR Axis I Disorders; SD: standard deviation; SDB: Sleep-disordered Breathing; SDS: Self-rating Depression Scale; SHQ: Sleep Habits questionnaire; SMD: Sleep-related Movement Disorders; SMH: Sleep Medicine History; TMB-10: Time Monitoring Behavior; USI: Uppsala Sleep Inventory. 


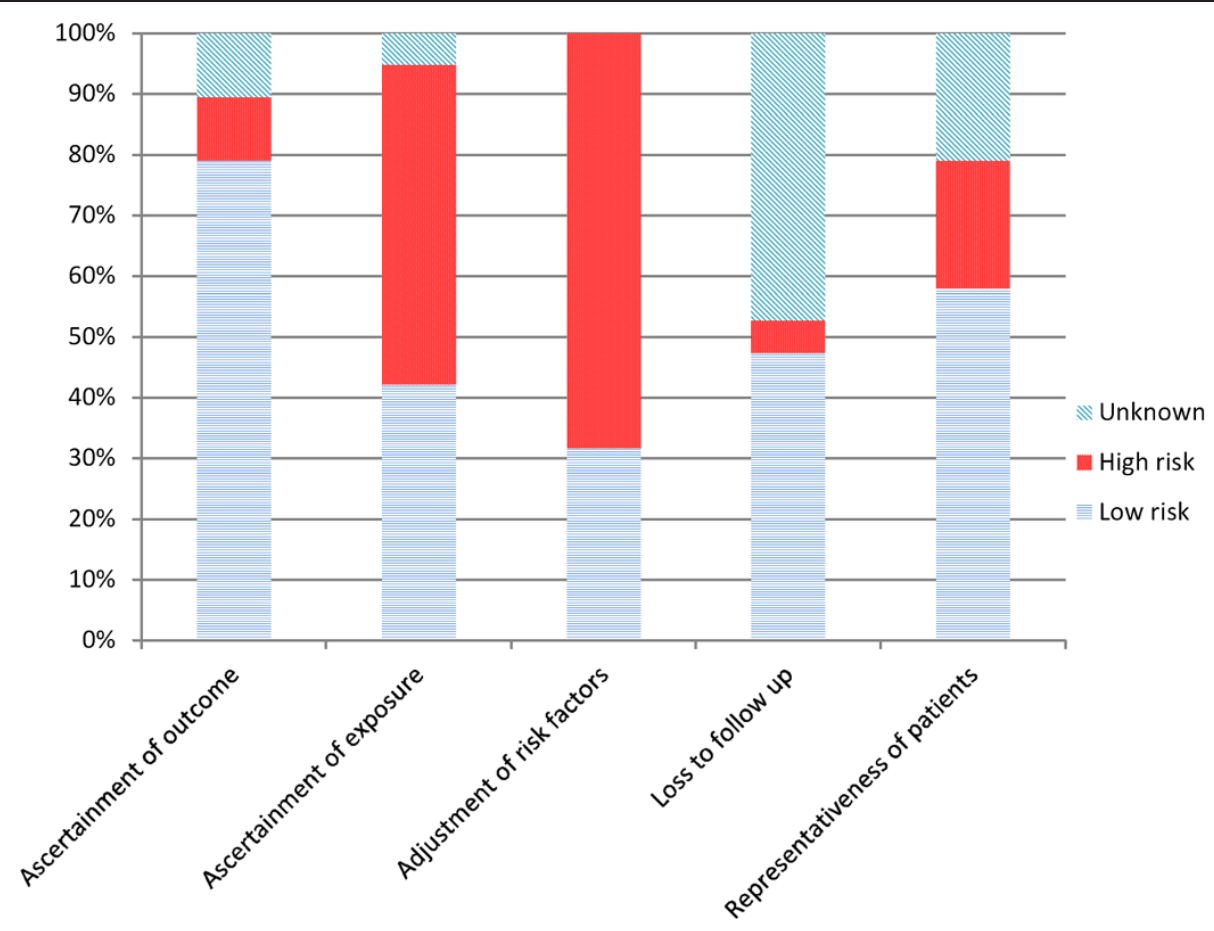

Figure 2 Quality assessment of the included studies.

with sleep disturbances and psychiatric diagnoses compared to those without sleep disturbances.

Nevertheless, the causal role or mechanism of sleep disturbances in suicidal behavior remains unclear. It is suggested that sleep disturbances exacerbates psychological distress [4,5], rendering psychiatric patients more vulnerable to suicidal behavior as a way to reduce or escape from such distress. There is also evidence that fatigue subsequent to sleep problems may impair problem solving and decrease emotion regulation increasing one's risk for suicidal behavior through vulnerability to impulsive behavior [29]. Other possibilities may include changes in sleep architecture that render one vulnerable to suicide. Certainly, future research is necessary to examine the specific mechanism of vulnerability because such knowledge may lead to an effective intervention. Research should establish whether there are specific problems in sleep or sleep architecture that promotes vulnerability, and should determine whether there are specific sleep profiles (for example, nightmares, insomnia, early morning awakening) that may discriminate between individuals who are at risk to suicide behaviors and those who actually complete suicide.

\section{Clinical implications}

Given the findings of this study, the presence of sleep disturbances in individuals with psychiatric illness may trigger the need for further evaluation of increased risk for suicide. In particular, clinicians evaluating psychiatric patients who report acute changes in sleep should be aware that this may represent a specific vulnerability for suicide, and a careful suicide risk assessment may be warranted. Correspondingly, a comprehensive suicide risk assessment may include an evaluation of sleep quality and maintenance. Screening measures such as the Pittsburgh Sleep Quality Index (PSQI) [30], which assesses sleep quality, efficiency, duration, disturbances, and daytime dysfunction, and has good reliability and validity in detecting sleep problems, may assist in this effort. A suicide risk assessment that includes evaluation of sleep disturbances may not only add to the estimation of risk, but it may also provide a potential target for intervention. This is particularly promising given that many of the previously established risk factors are person variables such as age, type of psychiatric disorder, and family history of suicide attempts, and thereby not amenable to intervention.

In terms of intervention, there is considerable evidence for the efficacy of Cognitive Behavioral Therapy for Insomnia (CBT-I) with large effect sizes found in meta-analytic studies [31]. Not only is CBT-I effective for treating primary sleep disorders, research examining CBT-I in patients with major depression and co-morbid insomnia found that the treatment led to improvements in both disorders [32]. Although CBT-I is considered to be a first-line treatment for insomnia [33], pharmacological treatments may also be given consideration for insomnia and other sleep problems. However, caution should be taken as studies found sedative-hypnotics were associated with increased suicidal 
behaviors [34-37]. A large cohort study demonstrated that receiving hypnotic prescriptions was associated with greater than three-fold increased hazards of death even when prescribed $<18$ pills/year. This association held in separate analyses for several commonly used hypnotics and for newer shorter-acting drugs [38].

\section{Limitations and strengths}

Strengths of the study include the comprehensive literature search, application of bias protection measures in the study selection, and careful evaluation of methodological quality. There are important limitations. Observational studies are subject to high risk of bias due to potential outcome confounding. Substantial heterogeneity was

Table 2 Subgroup analysis based on suicidal behaviors

\begin{tabular}{lllll}
\hline Suicidal behaviors & OR & $\mathbf{9 5 \%} \mathbf{C l}$ & $\boldsymbol{P}$ value & $\mathbf{I}^{\mathbf{2}}$ \\
\hline Ideation & 2.69 & $1.62,4.48$ & $<0.001$ & $\mathbf{7 3 . 5 \%}$ \\
Attempt & 4.36 & $2.28,8.33$ & $<0.001$ & $0.0 \%$ \\
Completed suicide & 1.59 & $1.17,2.17$ & $<0.01$ & $45.0 \%$ \\
\hline
\end{tabular}

observed across the studies. Publication bias may have also affected our results. At last, we observed substantial variations of how the included studies define sleep disturbances and suicidal behaviors, and of how these studies measure them. All of the above may affect our findings. Based on the Grading of Recommendations Assessment, Development and Evaluation (GRADE) methodology, the strength of the current evidence is low due to potential publication bias and heterogeneity [39].

Table 3 Subgroup analysis based on sleep disturbance type

\begin{tabular}{llllll}
\hline Sleep disturbance type & Studies $(\boldsymbol{n})$ & OR & $\mathbf{9 5 \%} \mathbf{C l}$ & $\boldsymbol{P}$ value & $\mathbf{I}^{\mathbf{2}}$ \\
\hline Insomnia & 11 & 2.66 & $1.74,4.07$ & $<0.001$ & $75.4 \%$ \\
Hypersomnia & 3 & 1.91 & $0.60,6.06$ & 0.27 & $85.8 \%$ \\
Parasomnia & 6 & 4.69 & $2.58,8.51$ & $<0.001$ & $0.0 \%$ \\
$\begin{array}{l}\text { Sleep-related } \\
\text { breathing disorder }\end{array}$ & 1 & 2.56 & $1.91,3.43$ & $<0.001$ & $\mathrm{n} / \mathrm{a}$ \\
Other/unclear & 7 & 4.16 & $1.96,8.81$ & $<0.001$ & $81.7 \%$
\end{tabular}

Sleep-related breathing disorder (SBD): only one study (Krakow, 2000) reported SBD and no objective test was used to confirm the diagnosis. 


\section{Conclusions}

The current evidence and the results of this systematic review and meta-analysis suggest that in patients with psychiatric diagnoses, sleep disturbances are associated with the increased risk of suicidal behaviors.

\section{Additional file}

Additional file 1: Database search strategy.

\section{Abbreviations}

95\% Cl: 95\% Confidence interval; CBT-I: Cognitive behavioral therapy for insomnia; GRADE: Grading of recommendations assessment development and evaluation; OR: Odds ratio; PRISMA: Preferred Reporting Items for Systematic Reviews and Meta-analyses; PSQI: Pittsburgh Sleep uality Index; PTSD: Post-traumatic stress disorder.

\section{Competing interests}

The authors declare that they have no competing interests.

\section{Authors' contributions}

SM carried out study design, study screening, data extraction, quality appraisal, and drafted the manuscript. AK participated in study design, study screening, data extraction, and critically revised the manuscript. LS conducted data extraction, drafted, and critically revised the manuscript. LP designed the search strategy and revised the manuscript. ZW carried out study design, study screening, data extraction, quality appraisal, data analysis, and drafted the manuscript. KB participated in data extraction, quality appraisal, and critically revised the manuscript. MHM carried out study design, advised on all methodological issues, drafted, and critically revised the manuscript. SM and ZW had equal contributions to the manuscript. All authors approved the final version of this manuscript.

\section{Author details}

'Division of Preventive Medicine, Mayo Clinic, 200 First Street SW, Rochester, MN 55905, USA. ${ }^{2}$ Fairview Clinics, Brooklyn Park, MN, USA. ${ }^{3}$ University of Wisconsin-Madison, Madison, WI 53706, USA. ${ }^{4}$ Department of Psychiatry \& Psychology, Mayo Clinic, Rochester, USA. ${ }^{5}$ Mayo Clinic Libraries, Mayo Clinic, Rochester, USA. ${ }^{6}$ Division of Health Care Policy and Research, Department of Health Sciences Research, Mayo Clinic, Rochester, USA. ${ }^{7}$ Mayo Clinic Robert D. and Patricia E. Kern Center for the Science of Health Care Delivery, Rochester, USA. ${ }^{8}$ Knowledge and Evaluation Research Unit, Mayo Clinic, Rochester, USA.

Received: 2 October 2013 Accepted: 12 February 2014 Published: 25 February 2014

\section{References}

1. Fawcett J, Scheftner WA, Fogg L, Clark DC, Young MA, Hedeker D, Gibbons R: Time-related predictors of suicide in major affective disorder. Am J Psychiatry 1990, 147:1189-1194.

2. Mann JJ, Waternaux C, Haas GL, Malone KM: Toward a clinical model of suicidal behavior in psychiatric patients. Am J Psychiatry 1999, 156:181-189.

3. Goldstein RB, Black DW, Nasrallah A, Winokur G: The prediction of suicide. Sensitivity, specificity, and predictive value of a multivariate model applied to suicide among 1906 patients with affective disorders. Arch Gen Psychiatry 1991, 48:418-422.

4. Breslau N, Roth T, Rosenthal L, Andreski P: Sleep disturbance and psychiatric disorders: a longitudinal epidemiological study of young adults. Biol Psychiatry 1996, 39:411-418.

5. Ford DE, Kamerow DB: Epidemiologic study of sleep disturbances and psychiatric disorders. An opportunity for prevention? JAMA 1989, 262:1479-1484.

6. Pigeon WR, Pinquart M, Conner K: Meta-analysis of sleep disturbance and suicidal thoughts and behaviors. J Clin Psychiatry 2012, 73:e1160-e1167.

7. Agargun MY, Kara H, Solmaz M: Sleep disturbances and suicidal behavior in patients with major depression. J Clin Psychiatry 1997, 58:249-251.
8. Li SX, Lam SP, Yu MW, Zhang J, Wing YK: Nocturnal sleep disturbances as a predictor of suicide attempts among psychiatric outpatients: a clinical, epidemiologic, prospective study. J Clin Psychiatry 2010, 71:1440-1446.

9. Moher D, Liberati A, Tetzlaff J, Altman DG: Preferred reporting items for systematic reviews and meta-analyses: the PRISMA statement. Ann Intern Med 2009, 151:264-269. W264.

10. Borenstein $M$, Cooper $H$, Hedges $L$, Valentine J: Effect sizes for continuous data. In The Handbook of Research Synthesis and Meta-Analysis. Edited by Cooper H, Hedges LV, Valentine JC. New York, NY: Russell Sage; 2009:221-235.

11. DerSimonian R, Laird N: Meta-analysis in clinical trials. Control Clin Trials 1986, 7:177-188.

12. McGirr A, Renaud J, Seguin M, Alda M, Benkelfat C, Lesage A, Turecki G: An examination of DSM-IV depressive symptoms and risk for suicide completion in major depressive disorder: a psychological autopsy study. J Affect Disord 2007, 97:203-209.

13. Nrugham L, Larsson B, Sund AM: Specific depressive symptoms and disorders as associates and predictors of suicidal acts across adolescence. $J$ Affect Disord 2008, 111:83-93.

14. Paffenbarger RS Jr, Lee IM, Leung R: Physical activity and personal characteristics associated with depression and suicide in American college men. Acta Psychiatr Scand Suppl 1994, 377:16-22.

15. Pompili M, Lester D, Grispini A, Innamorati M, Calandro F, lliceto P, De Pisa E, Tatarelli R, Girardi P: Completed suicide in schizophrenia: evidence from a case-control study. Psychiatry Res 2009, 167:251-257.

16. Sjostrom N, Hetta J, Waern M: Persistent nightmares are associated with repeat suicide attempt: a prospective study. Psychiatry Res 2009, 170:208-211.

17. Agargun MY, Kara H, Solmaz M: Subjective sleep quality and suicidality in patients with major depression. J Psychiatr Res 1997, 31:377-381.

18. Agargun MY, Cilli AS, Kara H, Tarhan N, Kincir F, Oz H: Repetitive and frightening dreams and suicidal behavior in patients with major depression. Compr Psychiatry 1998, 39:198-202.

19. Agargun MY, Kara H: Recurrent sleep panic, insomnia, and suicidal behavior in patients with panic disorder. Compr Psychiatry 1998, 39:149-151.

20. Agargun MY, Cartwright R: REM sleep, dream variables and suicidality in depressed patients. Psychiatry Res 2003, 119:33-39.

21. Chellappa SL, Araujo JF: Sleep disorders and suicidal ideation in patients with depressive disorder. Psychiatry Res 2007, 153:131-136.

22. Krakow B, Artar A, Warner TD, Melendrez D, Johnston L, Hollifield M, Germain A, Koss M: Sleep disorder, depression, and suicidality in female sexual assault survivors. Crisis 2000, 21:163-170.

23. Agargun MY, Besiroglu L, Cilli AS, Gulec M, Aydin A, Inci R, Selvi Y: Nightmares, suicide attempts, and melancholic features in patients with unipolar major depression. J Affect Disord 2007, 98:267-270.

24. Yoshimasu K, Sugahara H, Akamine M, Kondo T, Fujisawa K, Tokunaga S, Kiyohara C, Miyashita K, Kubo C: Sleep disorders and suicidal ideation in Japanese patients visiting a psychosomatic clinic in a university hospital. Sleep and Biological Rhythms 2006, 4:137-143.

25. Bjorngaard $\mathrm{JH}$, Bjerkeset O, Romundstad P, Gunnell D: Sleeping problems and suicide in 75,000 Norwegian adults: a 20 year follow-up of the HUNT I study. Sleep 2011, 34:1155-1159.

26. Li SX, Lam SP, Chan JWY, Yu MWM, Wing Y-K: Residual sleep disturbances in patients remitted from major depressive disorder: a 4-year naturalistic follow-up study. Sleep 2012, 35:1153-1161.

27. Krakow B, Ribeiro JD, Ulibarri VA, Krakow J, Joiner TE Jr: Sleep disturbances and suicidal ideation in sleep medical center patients. J Affect Disord 2011, 131:422-427.

28. Higgins JP, Thompson SG, Deeks JJ, Altman DG: Measuring inconsistency in meta-analyses. BMJ 2003, 327:557-560

29. Anderson C, Platten CR: Sleep deprivation lowers inhibition and enhances impulsivity to negative stimuli. Behav Brain Res 2011, 217:463-466.

30. Buysse DJ, Reynolds CF 3rd, Monk TH, Berman SR, Kupfer DJ: The Pittsburgh Sleep Quality Index: a new instrument for psychiatric practice and research. Psychiatry Res 1989, 28:193-213.

31. Morin CM, Culbert JP, Schwartz SM: Nonpharmacological interventions for insomnia: a meta-analysis of treatment efficacy. Am J Psychiatry 1994, 151:1172-1180.

32. Manber R, Edinger JD, Gress JL, San Pedro-Salcedo MG, Kuo TF, Kalista T: Cognitive behavioral therapy for insomnia enhances depression outcome in patients with comorbid major depressive disorder and insomnia. Sleep 2008, 31:489-495. 
33. Chesson AL Jr, Anderson WM, Littner M, Davila D, Hartse K, Johnson S, Wise M, Rafecas J: Practice parameters for the nonpharmacologic treatment of chronic insomnia, An American Academy of Sleep Medicine report. Standards of Practice Committee of the American Academy of Sleep Medicine. Sleep 1999, 22:1128-1133.

34. Allgulander $C$, Ljungberg L, Fisher LD: Long-term prognosis in addiction on sedative and hypnotic drugs analyzed with the Cox regression model. Acta Psychiatr Scand 1987, 75:521-531.

35. Carlsten A, Waern M: Are sedatives and hypnotics associated with increased suicide risk of suicide in the elderly? BMC Geriatr 2009, 9:20

36. Rod NH, Vahtera J, Westerlund H, Kivimaki M, Zins M, Goldberg M, Lange T: Sleep disturbances and cause-specific mortality: results from the GAZEL cohort study. Am J Epidemiol 2011, 173:300-309.

37. Belleville G: Mortality hazard associated with anxiolytic and hypnotic drug use in the National Population Health Survey. Can J Psychiatry 2010, 55:558-567.

38. Kripke DF, Langer RD, Kline LE: Hypnotics' association with mortality or cancer: a matched cohort study. BMJ Open 2012, 2:e000850.

39. Balshem $H$, Helfand M, Schunemann HJ, Oxman AD, Kunz R, Brozek J, Vist GE, Falck-Ytter Y, Meerpohl J, Norris S, Guyatt GH: GRADE guidelines: 3. Rating the quality of evidence. J Clin Epidemiol 2011, 64:401-406.

doi:10.1186/2046-4053-3-18

Cite this article as: Malik et al:: The association between sleep disturbances and suicidal behaviors in patients with psychiatric diagnoses: a systematic review and meta-analysis. Systematic Reviews 2014 3:18.

\section{Submit your next manuscript to BioMed Central and take full advantage of:}

- Convenient online submission

- Thorough peer review

- No space constraints or color figure charges

- Immediate publication on acceptance

- Inclusion in PubMed, CAS, Scopus and Google Scholar

- Research which is freely available for redistribution 